\title{
Using 3D Scanning for Improved Helmet Design
}

\author{
Simone MORLOCK*, Andreas SCHENK, Anke KLEPSER, Andreas SCHMIDT \\ Hohenstein Institut für Textilinnovation gGmbH, Boennigheim, Germany
}

DOI: $10.15221 / 16.190 \quad$ http://dx.doi.org/10.15221/16.190

\begin{abstract}
"One-size-fits-all' is definitely not a good approach to helmet design, especially for situations with the significant risk of head injury such as sports and industrial workplaces. Function of helmets is only given with perfect fit. But the complex geometry of heads was insufficiently defined by traditional measurement which captures length, width and circumference only as numerical values. Therefore, no head shape information was available so far. In contrast, 3D scanning-technology provides an innovative approach for analyzing head measurements and shapes.
\end{abstract}

Scientific analyses show remarkable variations in head shapes of humans within the same head circumference. Despite the real need for head protection systems, no reliable anthropometric German head data of women, men and children was available so far. The results of the Hohenstein R\&D project „Textile-based head protection systems"(IGF 16976 N) close this information gap. To collect exact three dimensional head data a specific scanning process was installed, heads of men, women and children were scanned and a database of 3D scan head data was created. Statistic evaluations as well as 3D shape analysis were conducted. Market share tables and virtual 3D shape models representing realistic head shapes of German population were generated and new innovative virtual 3D analysis methods for proving fit and ergonomic comfort were developed. 3D scanning-technology provides an innovative approach for the optimization of helmets in consideration of fit, functionality and design. In summary, the study results provide fundamental guidelines for helmet optimization in consideration of fit, functionality and design.

Keywords: 3D body scanning, head measurements, head shapes, size charts, helmet fit

\section{Introduction}

An increasing number of users - from children to seniors - are dealing with head protection for work and leisure. There are growing safety demands due to increasing awareness both in legal regulation and voluntary motivation. But only a helmet that fits and is worn consequently can prevent from severe head injuries. Despite the real need for head protection systems, no reliable anthropometric head data of women, men and children was available. Companies had no access to up-to-date-data or information about head shape or their percentage shares. Findings of morphological research show subjects with the same head circumference, but differing head shapes. [1] There is a wide variance between oval and round profiles. Figure 1 shows two individual male heads. Both with a head circumference of $58 \mathrm{~cm}$ corresponding head size 58 . Head shapes differ significantly illustrated by the cross-sections as well as head breadth, length and height.
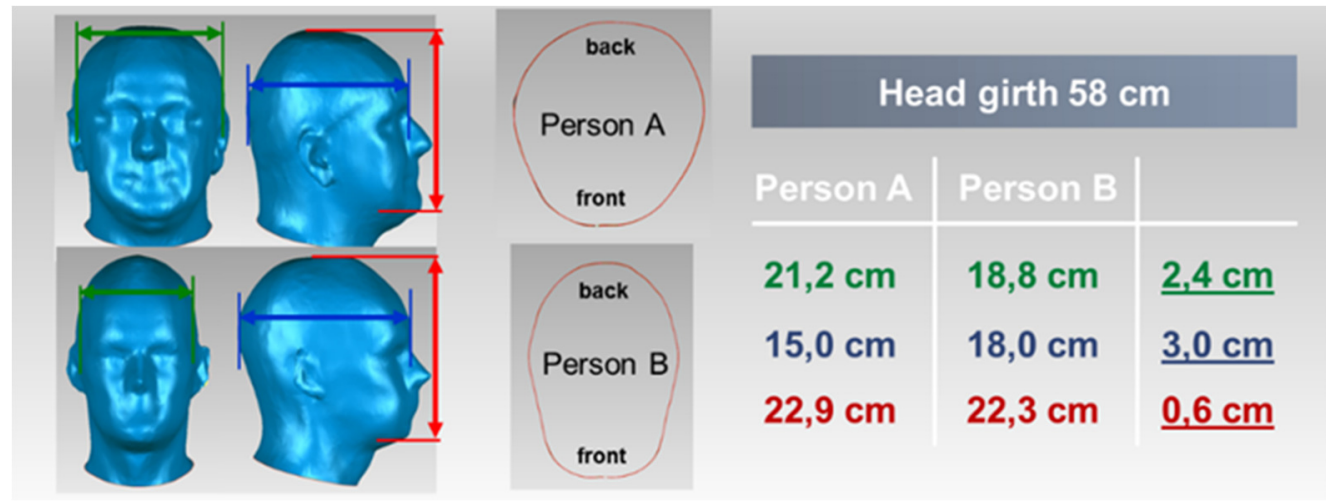

Fig. 1. Same head circumferences show differences between head morphology

*s.morlock@hohenstein.de; +49-7143-271-305; www.hohenstein.de 
A head breadth variance with a delta up to $4 \mathrm{~cm}$ was identified. This difference cannot be covered by only one helmet size or shape. Therefore, industry standards do not comply with the state of the art and anthropometric reality anymore. Figure 2 shows the range of head forms within the head size 58.

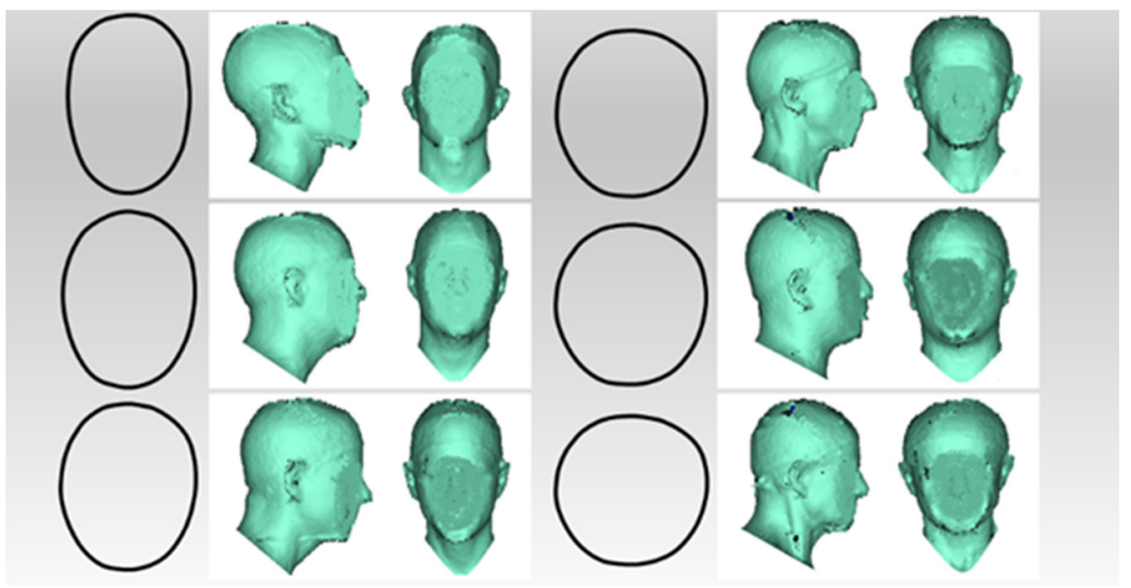

Fig. 2. Range of head shapes within the head size 58

There is an increasing number of research publications studying head shape and measurements [2] [3] [4] [5] [6] [7] [8] [9] [10] among others. This shows the great importance of the issue. Anthropometric findings from other countries may not be transferred to German population because ethnical groups differ in body morphology. This also applies to heads. [2] Therefore, German public funded project "Textile-based head protection systems" [1] was conducted. Within the project head measurements and shapes of about 6000 men, women and children of the German population were analyzed and statistically evaluated. All findings were summarized in a new head specific sizing system. Furthermore, 3D shape analyses were performed. Head types were defined and visualized via 3D head models. To generate a size range in line with market requirements, market shares were calculated.

The advantage of the new head sizing chart is the classification according to sizes. Unlike ergonomic procedures there are no percentiles described. For example, standard DIN 33402-2 "Ergonomie-Körpermaße des Menschen“ [11] provides only the 5, 50 and 95 percentile. An assignment to sizes is not possible as percentiles only give information about the percentage share smaller or bigger than the percentile, respectively.

\section{Methods}

\subsection{Anthropometric 3D head study}

Main requirement of the project success was a reasonable amount of target group body data. A representative 3D scan data pool $(n=20000)$ was available resulting from numerous anthropometric research projects [12] [13] [14] [15] [16] and others. This 3D body data was acquired by utilizing 3D bodyscanner Vitus Smart XXL. However, not all data files could not be used for statistic evaluation because of interference of hair. This will be further described below. A great amount of data had to be post processed with big effort, e.g. removing hair. Still, a lot of head data could not be used for the project and had to be excluded. Finally a sample of about 6000 heads of men, women and children was assembled.

To guarantee the validity of the statistic evaluation, the available scan data quality had to be verified. This was necessary because 3D bodyscanner Vitus Smart XXL is designed for full body acquisition, not for detailed hand, feet or head capturing. Therefore, a preliminary study with hand held scanner Creaform Ergo Handyscan was conducted to capture detailed head and face morphology. For this purpose, a specific head scanning process was developed (see Figure 3). 

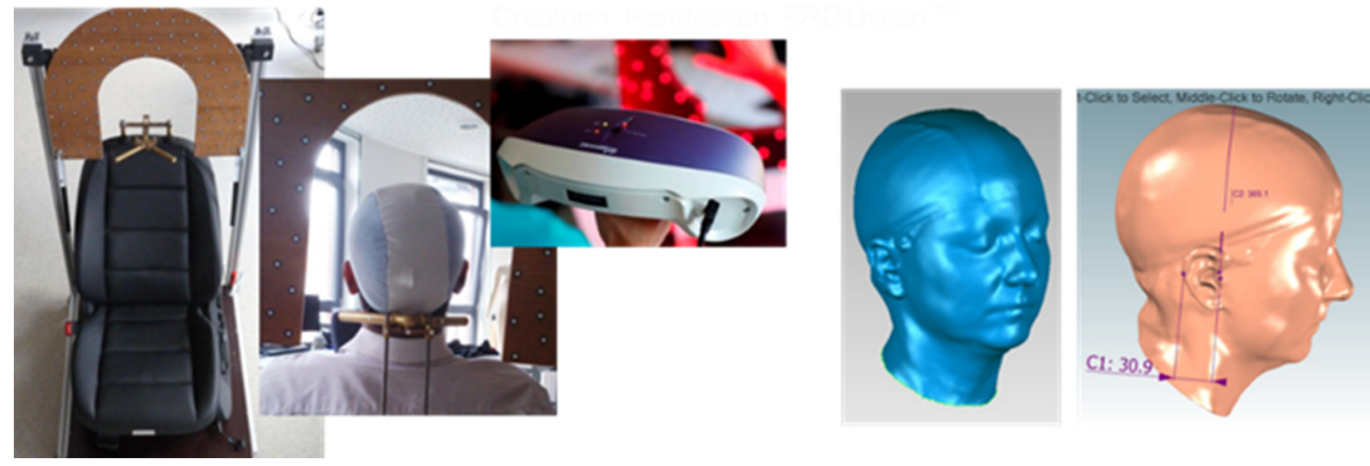

Fig. 3. 3D head scanning process with Creaform Ergo Handyscan

The challenge was to stabilize the head for reducing movements which falsify the scan and measurement results. 118 heads of men and women were scanned and a comprehensive number of measurements from each head has been taken. In addition some subjects' measurements were taken manually. The measurement by traditional measuring tape was performed with and without scan cap to analyze possible differences. These head-scans and measurement results were used for evaluating the head scans captured with Vitus Smart XXL. The objective was to identify the influence of different scanner systems as well as the influence of hair on the measurement results.

\subsection{Verifying data quality}

To verify data quality of available scan data several comparative studies were performed. The results of the measurements manually and digitally as well as the outcome of the different scanner systems were compared. Findings of the analyses were:

- Head measurements taken from Vitus Smart data are considered to be valid

- Head circumferences taken from Creaform Scans are around $2 \mathrm{~mm}$ smaller than from Vitus Scans

- On average, head circumferences taken manually are smaller than digital measurements

- In most cases, variation in dimension is bigger on women than on men

Reasons for measurement differences are numerous. They may be caused by the usage of differing scanner systems (resolution, technic etc.), by head movement during scan process, by inconsistency of measurement points, by interpersonal variance of measurement technics as well as by individual subjects' hair volumes. But, the main reason for measurement differences is hair volume. Figure 4 illustrates the described data analyses. Male subject on the left side is bald-headed. Female subject on the right side has got voluminous hair. Below the scan pictures there are the head measurements of Creaform scans, Vitus Scans as well as manually acquired. In addition, there are results of manual measurements with and without scan cap. Head circumference of the male subject show almost no differences. For the female subject with large hair volume, measurements differ significantly. Values range up to $2.9 \mathrm{~cm}$. Besides, scan cap influences values as well.
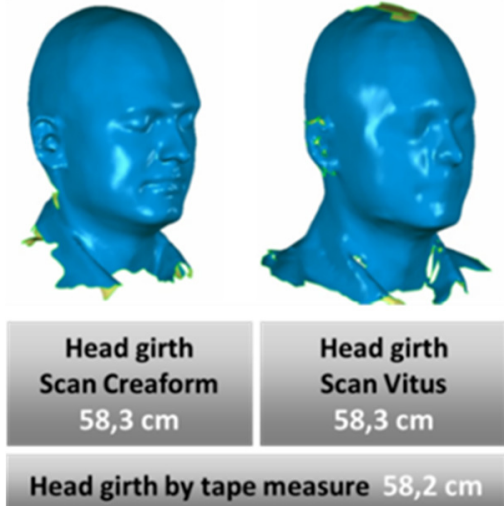

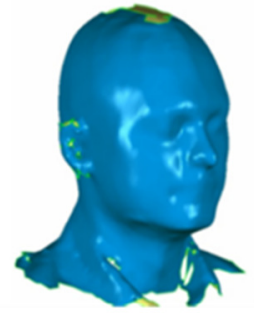

ead girth

are $58,2 \mathrm{~cm}$

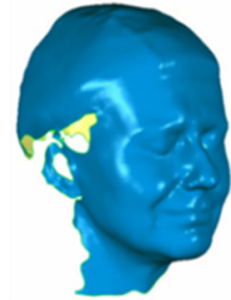

Head girth Scan Creaform $56,7 \mathrm{~cm}$

Head girth by tape measure without cap $54,0 \mathrm{~cm}$

Head girth by tape measure with cap $54,5 \mathrm{~cm}$

Fig. 4. Influence of hair volume on head circumference measurements 
The comparison shows that large hair volume unavoidable lead to clear measurement differences. The least impact has the scanner system itself. Although, Creaform system generates scans with higher resolutions and therefore better quality, the differences to scans of Vitus system are in average only $2 \mathrm{~mm}$. Compared to other influencing factors the importance is rather marginal. Big influence has the measurement technique - tape measure or 3D scanner technology - in relation to the tension of manual or digital tape measure. This significantly influences the effect on hair compression while measuring and thus the measuring results. In addition, in manually measurements interpersonal difference occur due to inconsistent and non-reproducible tension. Consequences are clear measurements differences. The larger the hair volume, the bigger are the measurement differences. Since, women do have often voluminous haircuts, the average measurements differences of female subjects are bigger than of male subjects.

Furthermore, scan cap influences results as well. Scan caps have to be worn to compress hair for gathering precise object surface because scanner does only capture surfaces. In former sizing surveys classic fabric swim caps were used. To get comparable scan results, the same type of caps was applied in the preliminary study. The disadvantage of those caps is the rather lose fit compared to neoprene, latex or silicon caps. For that reason, compression is less strong. The advantage is the simple and wrinkle free donning as well as ears are not covered by the caps. This is necessary to determine precise head breadth. If a cap bridges the head to ear distance, head breadth will increase due to hollow spaces. Besides, swim caps made of neoprene, latex or silicon are not easy to be donned on dry hair. Wrinkles occur or test subjects' hair cut might be ruined. Hence, acceptance of voluntary subjects is not likely for neoprene, latex or silicon caps.

As people do have differing hair volume, it is impossible to determine $100 \%$ accurate head measurements with state of the art techniques. As described before each scan had to be examined and poor quality had to be sorted out. In consequence, from the original 20000 available scans 2970 male, 1890 female, 800 boys' and 520 girls' heads were left to be analyzed. Furthermore, a correction factor was implemented. With this value every measurement influenced by hair, like head circumference, head breadth or head depth, were reduced by correction factor $1.7 \%$.

\subsection{Definition of head measurements}

The definition of anthropometric measure points is based on DIN 33402 [11] and ISO 7250 [17]. Using standardized methods guarantees comparability of research findings. In addition, new measurements, e.g. "Upper face breadth", "Distance head apex to eye" or "Distance head apex to upper ear base" were analyzed. Overall 25 head and face measurements were taken from each head. Figure 5 presents several head and face measurements, described in the final sizing charts.

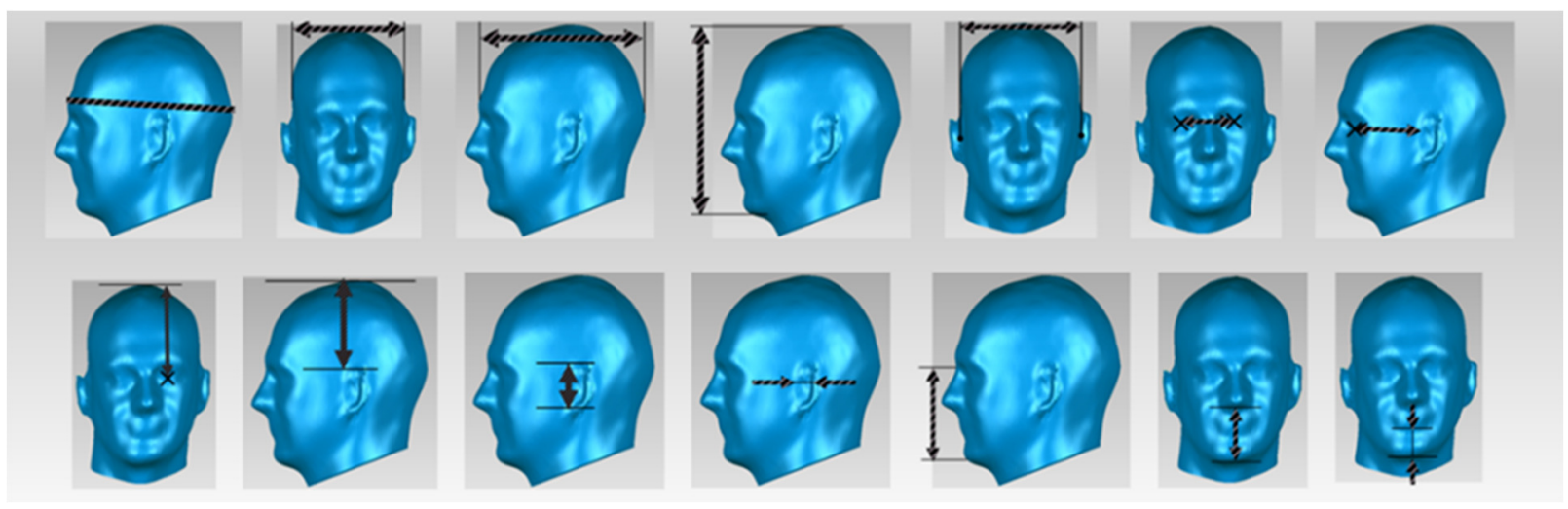

Fig. 5. Head and face measurements according to DIN 33 402, ISO 72510 and additional dimensions

\subsection{Fundamentals of the sizing chart development}

The sample of about 6000 data sets of men, women and children was the basis for the development of the sizing charts. On that basis, it was possible to perform a representative evaluation of the morphological head forms in relation to the 3-dimensional head shape. First, every measurement data set had to be double checked to ensure quality standards. Trained personnel took measurements interactively. Within the process of plausibility assessment, outlier were identified and erased. Therefore, a very precise and consistent database was available to perform the statistical analyses. 
The head measurements were statistically analyzed. Both, direct or indirect correlation of the measurements have been considered. In a multidimensional analysis averages, maximal and minimal values, scatter and percentage distribution were examined. As an example figure 6 shows the examination of the measurements "Head apex to eye" and "Distance eye to chin" in correlation to "Head circumference" and "Head height". Comparing the two dimensions makes it clear, that the distance head apex to eye is much more depending on "Head height" than the measurement distance "Eye to chin" does.
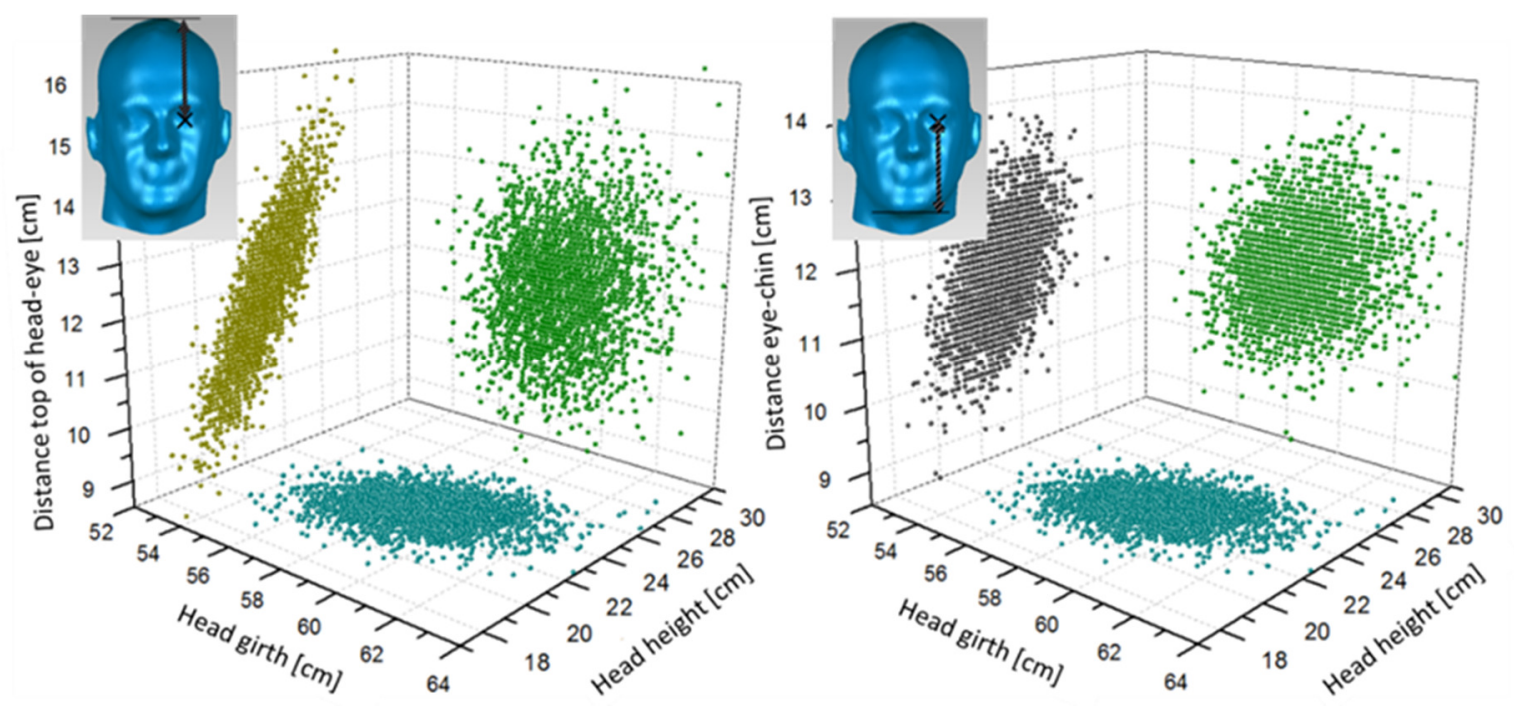

Fig. 6. Correlation analysis of distance "Head apex to eye" to "Head circumference" and "Head height"

"Head circumference" is the basic measurement and determines the head size. Primary measurements as "Head breadth", "Head depth" and "Head height" are correlated to "Head circumference". They are the foundation for defining head types. As a first step head types of the population were identified. Most important indicator was "Head breadth" and "Head depth". The correlation to head circumference answers question about head shape characteristics. Figure 7 illustrates the evaluation of the correlation of "Head breadth" and "Head circumference".

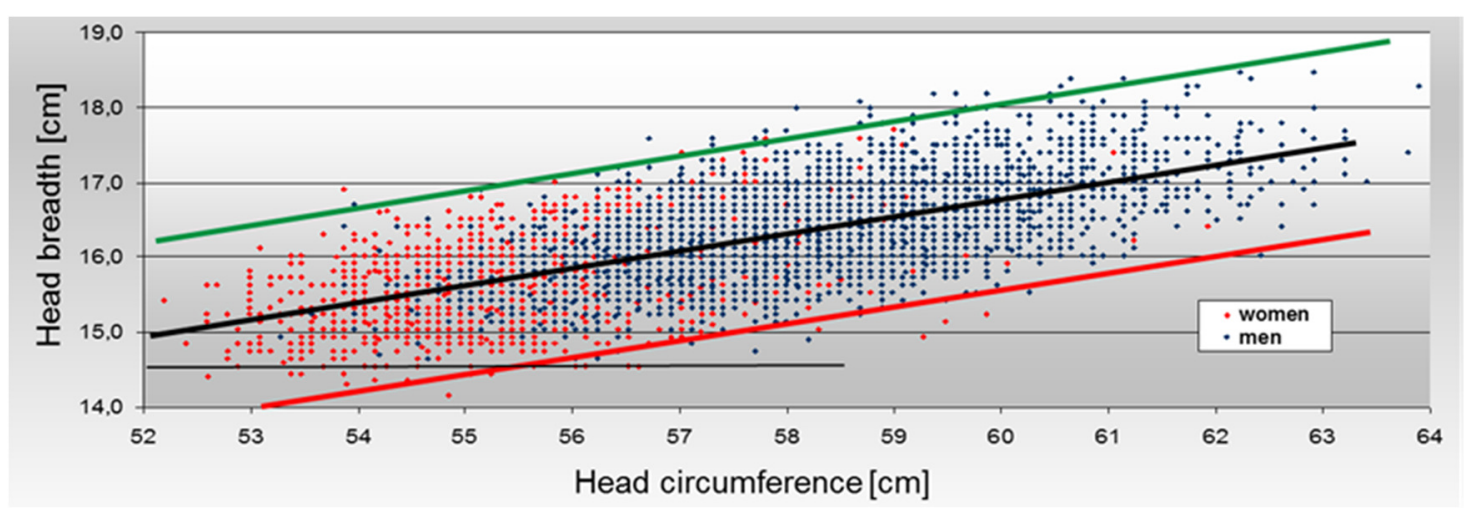

Fig. 7. Correlation "Head breadth" vs. "Head circumference" - men and women

The scatter diagram shows the correlation of both dimensions for men and women. The red dots represent female subjects and the blue dots represent male subject. The black trend line shows the clear correlation between the two measurements. Obviously men and women do have a similar "head circumference to head breadth ratio". This indicates similar head forms with the same "Head circumference". This could be confirmed by the following research results. Furthermore, the scatter diagram shows the variance of the dimension head breadth. For example, head circumference 58 presents a range of $3.4 \mathrm{~cm}$. The statistical analyses in combination with the $3 \mathrm{D}$ form analyses of the individual heads are the foundation of the head type definition (see chapter 3.2). 


\subsection{Generating virtual 3D head models}

3D head models were created on base of the statistical analyses of the head measurements as well as on the 3D shape analyses. These models give the maximum coverage in regard of the variance. The 3D models correlate with the new developed sizing charts. Utilizing software Geomagic Studio 2012 scans were edited and shaped. The methodical approach was as follows: 3D scans of a specific size cluster are chosen. Parameters were head circumference, breadth, depth, height and further secondary measurements. Scan data (point cloud) was edited and converted into a polygon model. On this basis the average heads were calculated. They were edited and shaped to create watertight surface models. In the process, the acceptable degree of idealization had to be determined and checked. Finally, a verification and adjustment of the average 3D head shapes related to the sizing chart were performed.

\subsection{D Helmet fitting}

A 3D based method for helmet fitting was developed based on virtual comparing of head and helmet form. Necessary condition is the digitalization of the helmets by scanning technology. Virtually the helmet can be donned on the head by 3D software Geomagic - individual scans as well as average 3D models may be used. Analyzing cross sections and executing 3D distance analyses allows examining possible fitting problems.

\section{Results and Discussion}

\subsection{Percentage distribution of head sizes}

Figure 8 shows the size distribution of 2970 male and 1890 female subjects with an age range from 18 to 85 years.

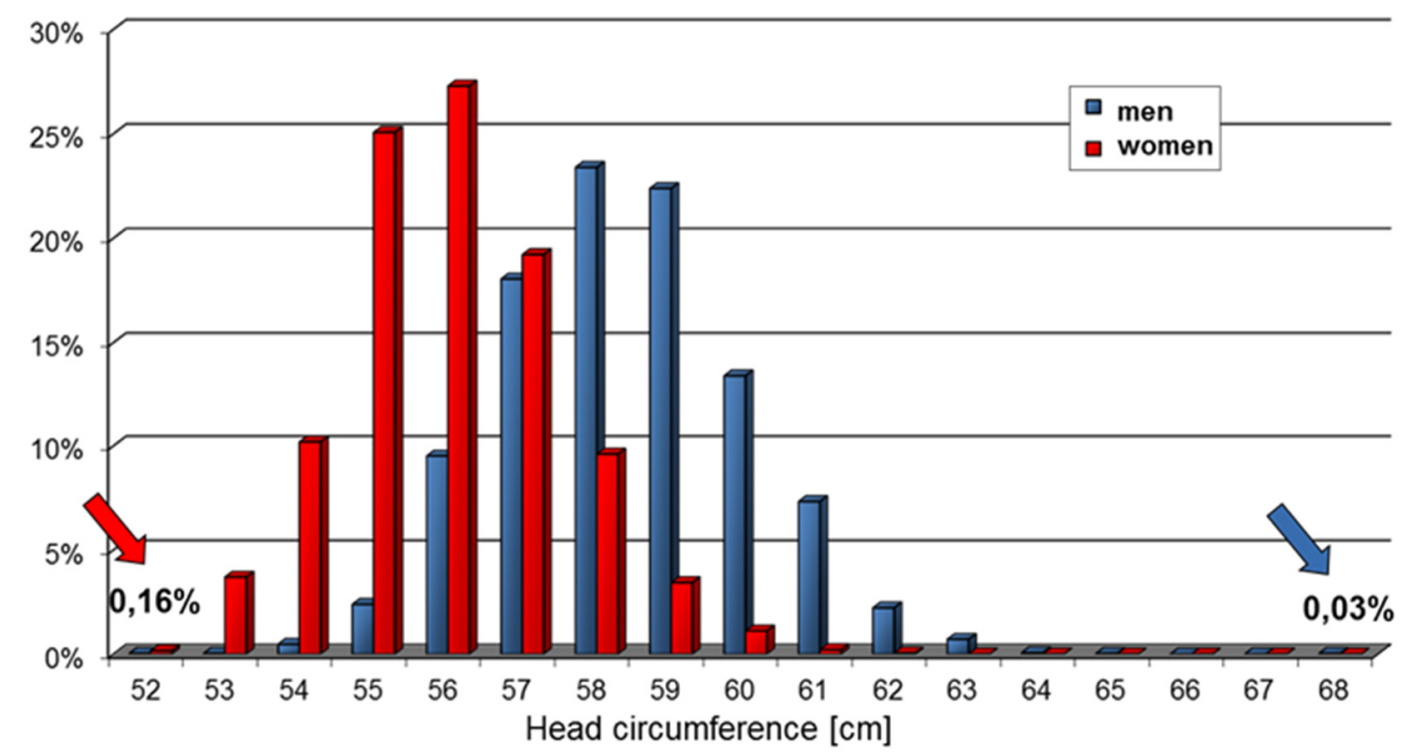

Fig. 8. Market shares - men and women

Evaluation was performed with adjusted head circumference values reduced by correction factor $1.7 \%$ (see chapter 2.2). The bar diagram illustrates the most important market shares. For men the major part is at head circumference 58 and $59 \mathrm{~cm}$. Women have smaller heads in average. The major part for female subjects is at head circumference 55 and $56 \mathrm{~cm}$. The smallest measured head circumference was $52 \mathrm{~cm}$ and the biggest was $68 \mathrm{~cm}$. These sizes are rather marginal but they show the complete range of sizes needed for head protection systems.

The percentage size distribution of boys $(n=800)$ and girls $(n=520)$ is shown in figure 9 and 10. Age range is between 6 and 17 years. Similar to the evaluation of the adult subjects the correction factor was considered and applied. The bar diagrams illustrate that it is of great importance to differentiate between the age groups. 


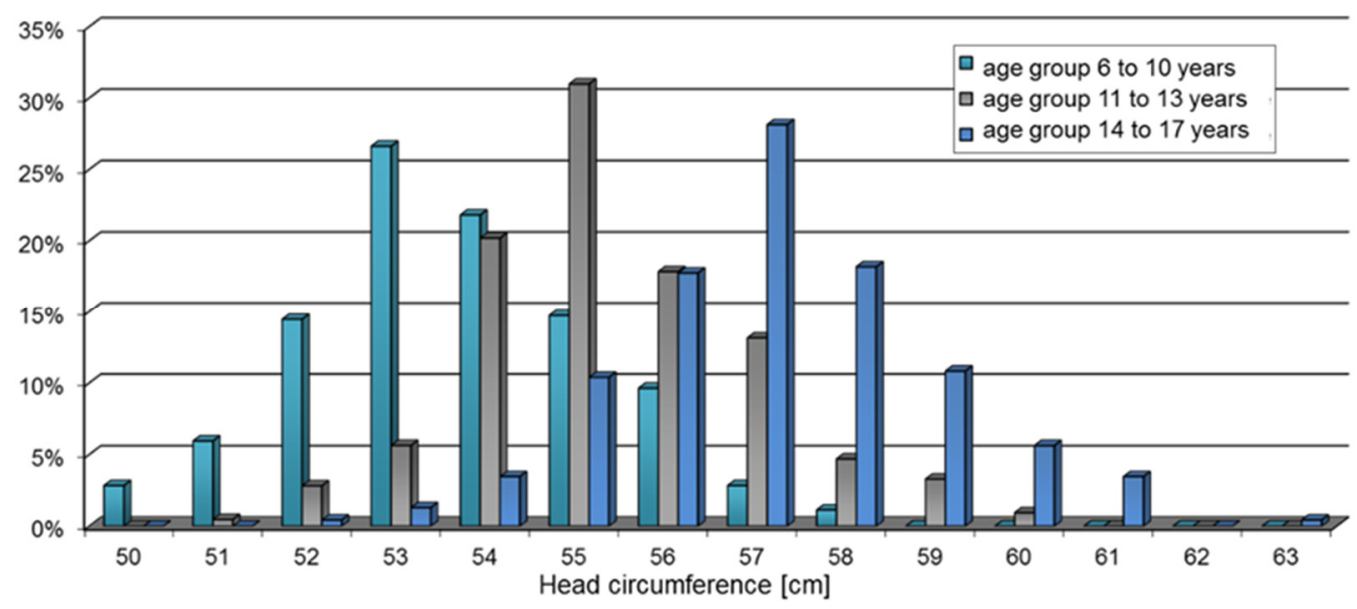

Fig. 9. Percentage distribution according to head circumference in each age group - boys

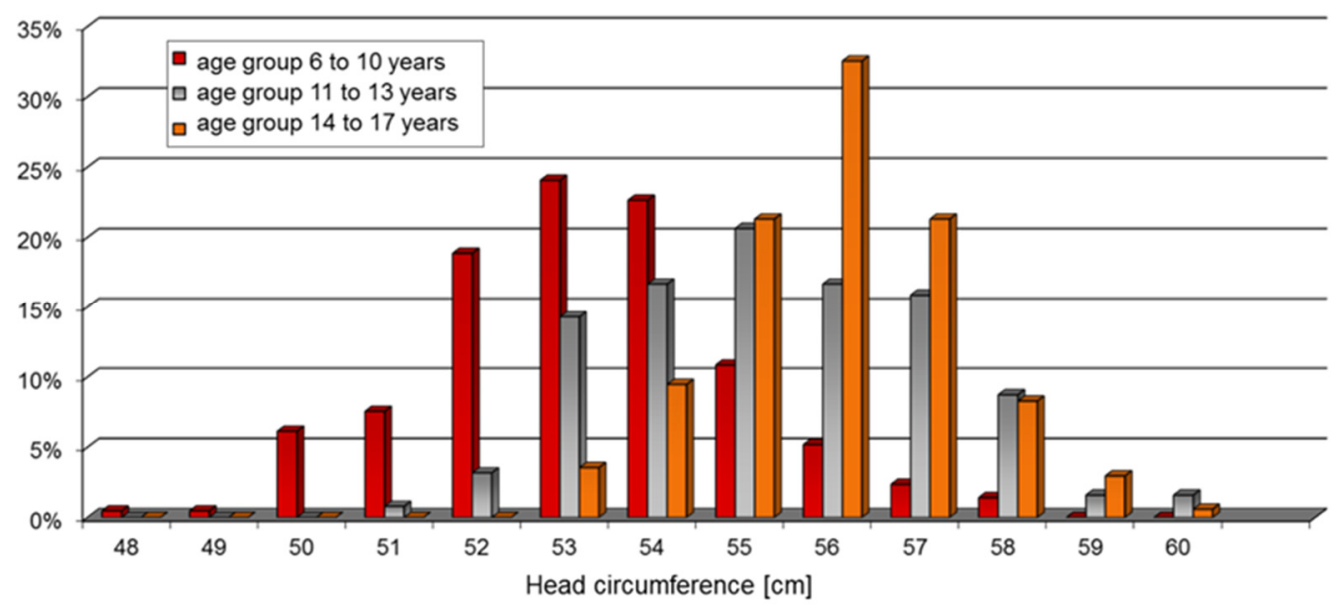

Fig. 10. Percentage distribution according to head circumference in each age group-girls

\subsection{Definition of head types}

The parameters to determine the head shape are head breadth and depth. The statistical evaluation of the two measurements indicated that five head types are needed to cover the wide range of shapes (see figure 11). Between the head types "Head breadth" increases $0.8 \mathrm{~cm}$ and "Head depth" increases $0.4 \mathrm{~cm}$. The five head types allow best market coverage with well-fitting products. If helmet shapes are more flexible, the scale of values can be easily adapted, e.g. for double sizes.
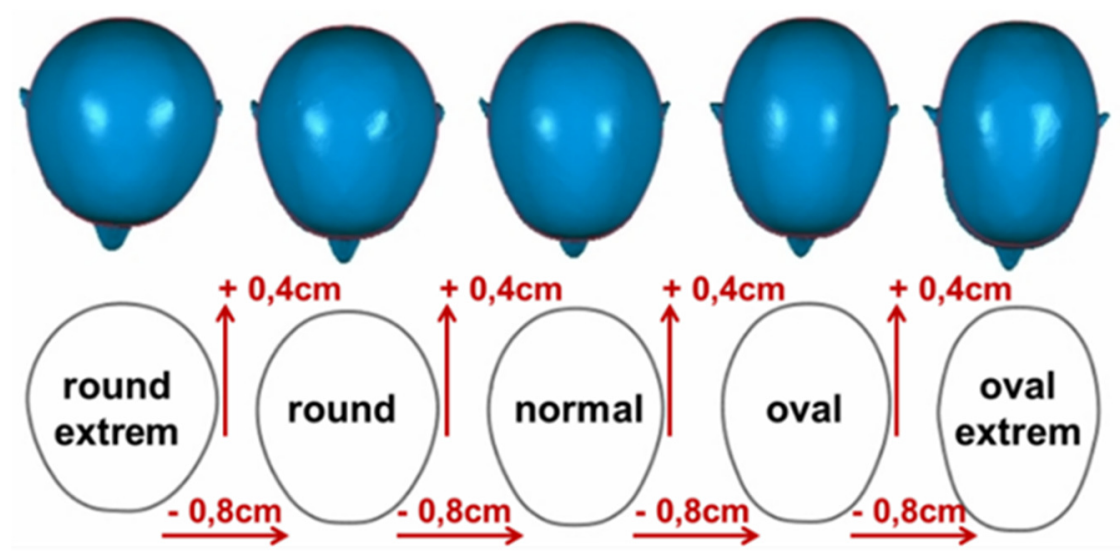

Fig. 11. Visualization of cross sections of the 5 defined head types - men 
Head type normal covers $63 \%$ of the male population and $62.5 \%$ of the female population. Nevertheless, $37 \%$ or $37.5 \%$ of prospective clients do have other head types and need helmet shapes matching to their specific geometry.

Besides head breadth and depth the height of the head is another important primary measurement. "Head height" has an impact on the evaluation and cluster formation of any other head length, e.g. "Distance head apex to eye". First, range of "Head height" was analyzed. Men's cluster showed $8 \mathrm{~cm}$ differences and women's cluster showed $7.2 \mathrm{~cm}$ differences in maximum. Five head height types with $2 \mathrm{~cm}$ differences were defined (see Figure 12).

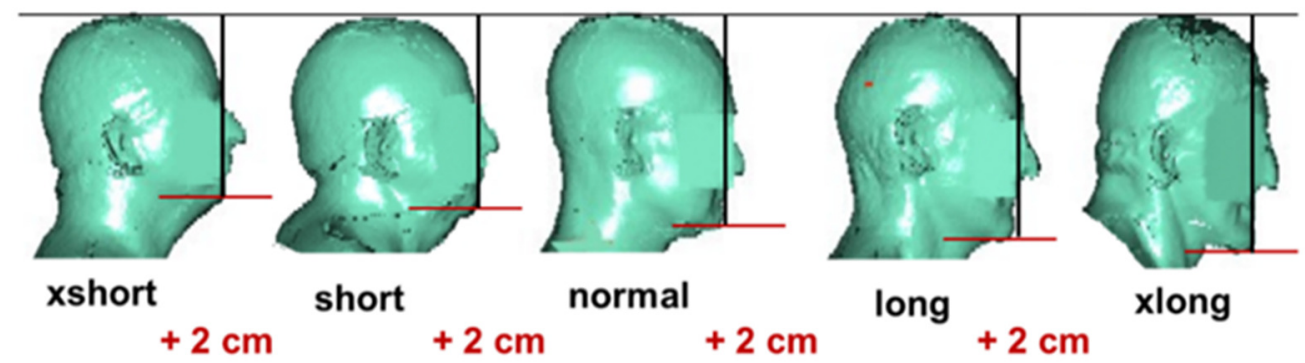

Fig.12. Five head height types

In contrary to breadth and depth, "Head height" values of men and women differ. Female subjects show on average $0.5 \mathrm{~cm}$ shorter "Head height" than male. The head height type normal covers $58.2 \%$ of the male market. Yet, the types short and long are not at all niche market. Each of them has a share of almost $20 \%$. Market shares for female customers show similar distribution: $60.8 \%$ type normal, almost $20 \%$ share for type short and long. Head types extra short and extra long are rather marginal but they show the complete range of head heights.

\subsection{Sizing charts for head and face measurements}

Findings of statistical analyses were combined in a new sizing system. A sizing chart including 14 head and face measurements was developed. Figure 13 presents an extract of the sizing chart with "Head breadth" and "Cranial base width".

\begin{tabular}{|c|c|c|c|c|c|c|c|c|c|c|c|c|c|c|c|c|c|c|}
\hline & type $s$ & 48 & 49 & 50 & 51 & 52 & 53 & 54 & 55 & 56 & 57 & 58 & 59 & 60 & 61 & 62 & 63 & 64 \\
\hline \multirow[t]{5}{*}{ Head breadth } & oval extrem & 12.4 & 12.6 & 12.8 & 13.1 & 13.3 & 13.5 & 13.7 & 14.0 & 14.3 & 14.5 & 14.7 & 14.9 & 15.2 & 15.5 & 15.7 & 15.9 & 16.2 \\
\hline & oval & 13.2 & 13.4 & 13.6 & 13.9 & 14.1 & 14.3 & 14.5 & 14.8 & 15.1 & 15.3 & 15.5 & 15.7 & 16.0 & 16.3 & 16.5 & 16.7 & 17.0 \\
\hline & normal & 14 & 14.2 & 14.4 & 14.7 & 14.9 & 15.1 & 15.3 & 15.6 & 15.9 & 16.1 & 16.3 & 16.5 & 16.8 & 17.1 & 17.3 & 17.5 & 17.8 \\
\hline & round & 14.8 & 15 & 15.2 & 15.5 & 15.7 & 15.9 & 16.1 & 16.4 & 16.7 & 16.9 & 17.1 & 17.3 & 17.6 & 17.9 & 18.1 & 18.3 & 18.6 \\
\hline & round extrem & 15.6 & 15.8 & 16 & 16.3 & 16.5 & 16.7 & 16.9 & 17.2 & 17.5 & 17.7 & 17.9 & 18.1 & 18.4 & 18.7 & 18.9 & 19.1 & 19.4 \\
\hline
\end{tabular}

\begin{tabular}{|l|l|l|l|l|l|l|l|l|l|l|l|l|l|l|l|l|l|}
\hline type size & 48 & 49 & 50 & 51 & 52 & 53 & 54 & 55 & 56 & 57 & 58 & 59 & 60 & 61 & 62 & 63 & 64 \\
\hline
\end{tabular}

\begin{tabular}{|c|c|c|c|c|c|c|c|c|c|c|c|c|c|c|c|c|c|c|}
\hline \multirow{5}{*}{$\begin{array}{l}\text { Cranial Base Width } \\
\text { men }\end{array}$} & oval extrem & & & & & 13.1 & 13.3 & 13.5 & 13.7 & 13.9 & 14.1 & 14.3 & 14.5 & 14.7 & 14.9 & 15.1 & 15.3 & 15.5 \\
\hline & oval & & & & & 13.6 & 13.8 & 14.0 & 14.2 & 14.4 & 14.6 & 14.8 & 15.0 & 15.2 & 15.4 & 15.6 & 15.8 & 16.0 \\
\hline & normal & & & & & 14.1 & 14.3 & 14.5 & 14.7 & 14.9 & 15.1 & 15.3 & 15.5 & 15.7 & 15.9 & 16.1 & 16.3 & 16.5 \\
\hline & round & & & & & 14.6 & 14.8 & 15.0 & 15.2 & 15.4 & 15.6 & 15.8 & 16.0 & 16.2 & 16.4 & 16.6 & 16.8 & 17.0 \\
\hline & round extrem & & & & & 15.1 & 15.3 & 15.5 & 15.7 & 15.9 & 16.1 & 16.3 & 16.5 & 16.7 & 16.9 & 17.1 & 17.3 & 17.5 \\
\hline \multirow{5}{*}{$\begin{array}{l}\text { Cranial Base Width } \\
\text { women }\end{array}$} & oval extrem & & & & & 12.6 & 12.8 & 13.0 & 13.2 & 13.4 & 13.6 & 13.8 & 14.0 & 14.2 & 14.4 & 14.6 & 14.8 & 15.0 \\
\hline & oval & & & & & 13.1 & 13.3 & 13.5 & 13.7 & 13.9 & 14.1 & 14.3 & 14.5 & 14.7 & 14.9 & 15.1 & 15.3 & 15.5 \\
\hline & normal & & & & & 13.6 & 13.8 & 14.0 & 14.2 & 14.4 & 14.6 & 14.8 & 15.0 & 15.2 & 15.4 & 15.6 & 15.8 & 16.0 \\
\hline & round & & & & & 14.1 & 14.3 & 14.5 & 14.7 & 14.9 & 15.1 & 15.3 & 15.5 & 15.7 & 15.9 & 16.1 & 16.3 & 16.5 \\
\hline & round extrem & & & & & 14.6 & 14.8 & 15.0 & 15.2 & 15.4 & 15.6 & 15.8 & 16.0 & 16.2 & 16.4 & 16.6 & 16.8 & 17.0 \\
\hline \multirow{5}{*}{$\begin{array}{l}\text { Cranial Base Width } \\
\text { boys }\end{array}$} & oval extrem & & & & & & & & & & & & & & & & & \\
\hline & oval & 12.1 & 12.3 & 12.5 & 12.7 & 12.9 & 13.1 & 13.3 & 13.5 & 13.7 & 13.9 & 14.1 & 14.3 & 14.5 & 14.7 & & & \\
\hline & normal & 12.6 & 12.8 & 13.0 & 13.2 & 13.4 & 13.6 & 13.8 & 14.0 & 14.2 & 14.4 & 14.6 & 14.8 & 15.0 & 15.2 & & & \\
\hline & round & 13.1 & 13.3 & 13.5 & 13.7 & 13.9 & 14.1 & 14.3 & 14.5 & 14.7 & 14.9 & 15.1 & 15.3 & 15.5 & 15.7 & & & \\
\hline & round extrem & & & & & & & & & & & & & & & & & \\
\hline \multirow{5}{*}{$\begin{array}{l}\text { Cranial Base Width } \\
\text { girls }\end{array}$} & oval extrem & & & & & & & & & & & & & & & & & \\
\hline & oval & 11.6 & 11.8 & 12.0 & 12.2 & 12.4 & 12.6 & 12.8 & 13.0 & 13.2 & 13.4 & 13.6 & 13.8 & 14.0 & 14.2 & & & \\
\hline & normal & 12.1 & 12.3 & 12.5 & 12.7 & 12.9 & 13.1 & 13.3 & 13.5 & 13.7 & 13.9 & 14.1 & 14.3 & 14.5 & 14.7 & & & \\
\hline & round & 12.6 & 12.8 & 13.0 & 13.2 & 13.4 & 13.6 & 13.8 & 14.0 & 14.2 & 14.4 & 14.6 & 14.8 & 15.0 & 15.2 & & & \\
\hline & round extrem & & & & & & & & & & & & & & & & & \\
\hline
\end{tabular}

Fig. 13. Extract of the sizing charts - "Head breadth" and "Cranial base width" 
Similarities and measurement differences between age groups and sex were identified and reflected in the chart. The charts include five head types - oval extreme, oval, normal, round, extra round - as well as five head heights - extra short, short, normal, long, extra long. The size range starts at size 48 and ends at size 64. Adult head circumference range is from 52 to $62 \mathrm{~cm}$, children's circumferences range from 48 to $60 \mathrm{~cm}$. The sizing charts for adults represent the complete age range. Regarding primary measurements "Head breadth" and "Head depth", this applies for children, too. Values are covering grown-ups as well as infants. Measurement differences between children and adults are minimal and range from 1 to $3 \mathrm{~mm}$. For that reason, it was not considered useful to develop a specific children's chart. Thus, secondary measurements hat to be described separately.

\subsection{Representative 3D head models}

Following, the generated virtual average 3D heads are illustrated. They are representing and visualizing the measurements of the new developed sizing chart. Figure 14 shows men's heads in type normal and sizes 56, 58, 60 and 62. Figure 15 is visualizing men's head types oval extreme, oval, normal, round and round extreme in size 58. The average female heads in figure 16 are type normal and in sizes 54, 56 and 58. In figure 17 average boys' heads in type normal in sizes 52, 54, 56 and 58 are presented.

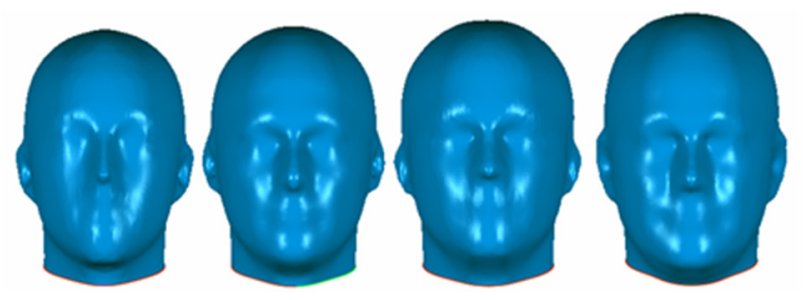

Fig.14. Representative 3D head models men - sizes 56, 58, 60 und 62 - head type normal

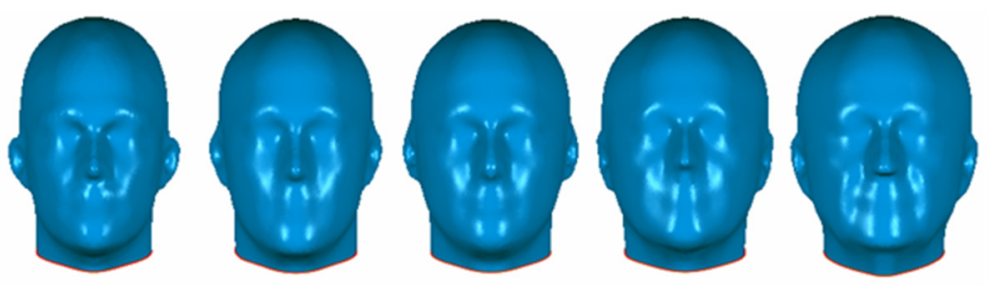

Fig. 15. Representative 3D head models men - size 58 - head types oval extreme, oval, normal, round, round extr.

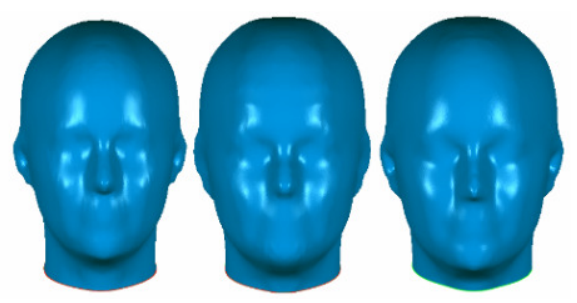

Fig. 16. Representative 3D head models women - sizes 54, 56, und 58 - head type normal

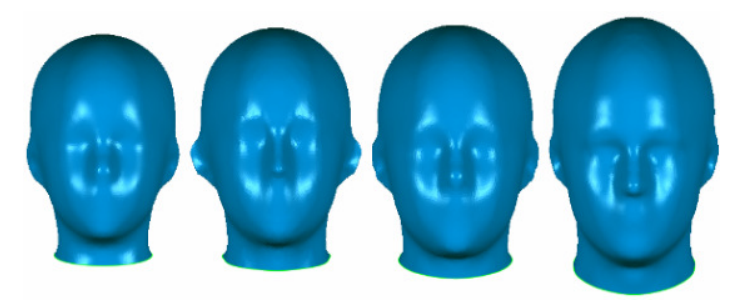

Fig. 17. Representative 3D head models boys - sizes 52, 54, 56, und 58 - head type normal 


\subsection{Fitting results}

Finally, the ergonomic comfort of helmets was analyzed. The distance gaps between head geometry and real helmet inside by using 3D scanning technology were evaluated. This method allows the virtual testing of helmet fitting based on head measurements and 3D head shape models. Figure 18 shows two 3D fitting analyses with individual head scans utilizing Geomagic Studio 2012. On the left a well-fitting helmet is illustrated. Cross section shows good form accordance. There is only marginal penetration of the textile inner lining which is compressed by the subjects head. The result is confirmed by transparent presentation of helmet on subjects head scan. On the right side an ill-fitting helmet is presented. Cross sections show clear penetration of inner lining. The visualization of the transparent helmet on the subject confirms the finding.

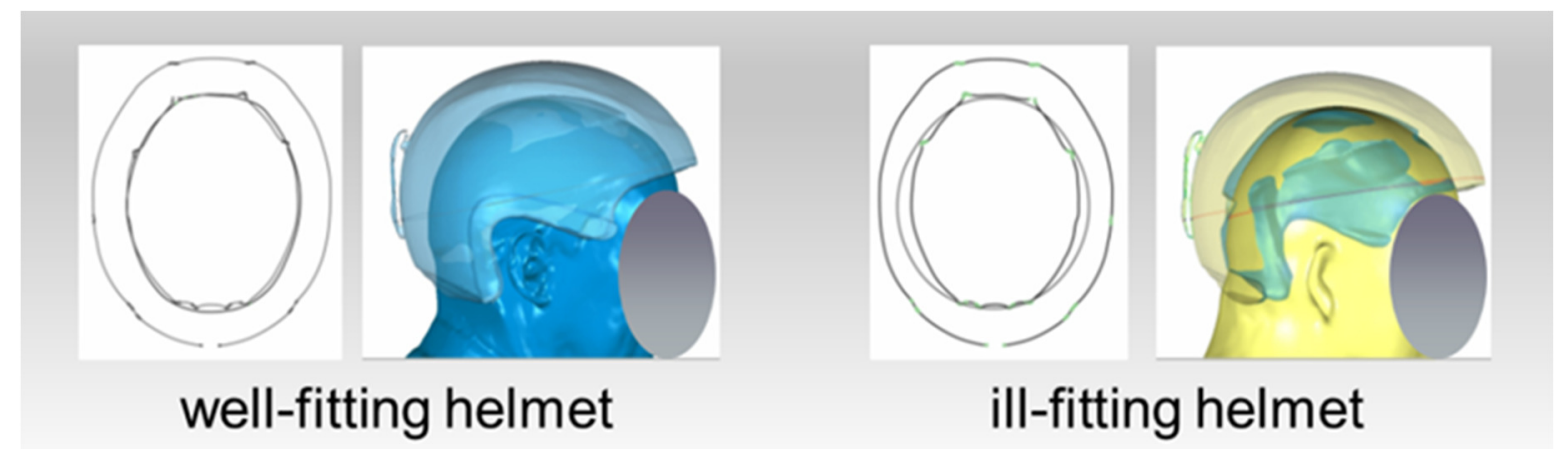

Fig. 18. Example for 3D helmet fit analysis - well and ill-fitting helmet

Further research is needed on virtual fitting analyses. In addition, objective and reproducible textile parameters regarding deformability of inner linings as well as information of pressure zones on the human head are required to obtain profound fitting results.

\section{Conclusions}

The results of the scientific research provide fundamental product developing guidelines which correspond to customer's requirements. [18] Head measurements and 3D virtual models give comprehensive geometrically information for optimized product development. The present engineer standards can be adapted to the state-of-the-art.

With the development of the head sizing charts providing size related head data a foundation is given to produce optimized helmet fit for differing head types. On the basis of a representative sample market shares with optimal coverage were identified. Analyses showed that largest source of failures are human hair. Varying hair volume leads to differences in head measurements regardless of measurement technic. These deviations are unavoidable. In addition, hair influences helmet fit and wearing comfort. Further research is needed.

The statistical analyses of children's head measurements indicated that some differences in face dimensions are growth-related. Head and face proportions are significantly changing with cranium growth. While the upper part of head is changing only a little, the lower facial part is changing significantly. This could not be completely presented within this limited space. In regard of the face measurements further clusters in age groups are necessary.

\section{Acknowledgment}

The IGF project $16976 \mathrm{~N}$ by the research association Forschungskuratorium Textil e.V., Reinhardtstraße 12-14, 10117 Berlin, is financed through the AiF within the framework of the program for promotion of cooperative industrial research (IGF) by the German Federal Ministry for Economic Affairs and Energy based on a resolution by the German Bundestag. 


\section{References}

[1] S. Morlock, M. Harnisch, H. Mucha, „Grundsatzuntersuchung zur Optimierung textilbasierter Kopfschutzsysteme“, IGF 16976 N, Hohenstein Institut für Textilinnovation gGmbH, Boennigheim, Germany, 2014

[2] AE International, "CAESAR - The most comprehensive source for body measurement data ", http://store.sae.org/caesar, accessed 2016.

[3] B. Bradtmiller, M. Friess, "A Head-and-Face anthropometric survey of U.S. respirator users", National Institute for Occupational Safety and Health (NIOSH), 2004.

[4] SizeChina.com, "SizeChina.com", http://www.sizechina.com, accessed 2016.

[5] Y. Kelkel., M. Foissac., L. Baly, "A simple and standardized method for analysing head and face morphology of a population sample", in Proc. of Int. Conf. on 3D Body Scanning Technologies, Lugano, Switzerland, 2010, pp. 222-228.

[6] University of Pittsburgh, "FaceBase - 3D Facial Norms Database", https://www.facebase.org/facial_norms, accessed 2016.

[7] P. Meunier, D. Tack, A. Ricci et al., "Helmet accommodation analysis using 3D laser scanning", Defence and Civil Institute of Environmental Medicine, 2000.

[8] C. R. Harrison, K.M. Robinette, "Principles of Fit to Optimize Helmet Sizing", Air Force Research Laboratory, 2006.

[9] V. Joshi, S. Swamy, P. Biswal., "Sizing trials of a prototype aircrew helmet: Lessons re-learnt", in Journal of Indian Journal of Aerospace Medicine 2009, Med 53(2), S. 44 - 54.

[10] L. Goto, J. F. M. Molenbroek., R. H. M. Goossens, "3D Anthropometric Data Set of the Head and Face of Children Aged 0.5-7 Years for Design Applications", in Proc. of 4th International Conference on 3D Body Scanning Technologies, 19-20 November 2013, Long Beach CA, USA, 2013, pp. $157-165$.

[11] DIN Deutsches Institut für Normung e.V., „DIN 33402-2: Ergonomie - Körpermaße des Menschen - Teil 2: Werte“, Berlin, Germany, 2005.

[12] Human Solutions GmbH \& Hohenstein Institute, "SizeGERMANY", www.sizegermany.de, accessed 2016.

[13] S. Morlock, E. Wendt, E. Kirchdörfer et al., "Grundsatzuntersuchung zur Konstruktion passformgerechter Bekleidung für Frauen mit starken Figuren", IGF 15144 BG, Bekleidungsphysiologisches Institut Hohenstein, Technische Universität Dresden, Boennigheim, Germany, 2009.

[14] S. Morlock, M. Harnisch et al., „Passformgerechte und bekleidungsphysiologisch optimierte Bekleidungskonstruktion für Männer mit großen Größen unterschiedlicher Körpermorphologien“, IGF 17460 N, Hohenstein Institut für Textilinnovation gGmbH, Boennigheim, Germany, 2015.

[15] E. Kirchdörfer, A. Mahr-Erhardt, H. Scheck, "Körpermaße, Marktanteile und Konstruktionsgrundlagen für Miederbekleidung“, Band 143, Forschungsgemeinschaft Bekleidungsindustrie, Hohenstein Institute, Köln, Germany, 2001.

[16] E. Kirchdörfer, A. Mahr-Erhardt, "Oberbekleidung für Frauen über 60 Jahre - Körperdimensionen, Größenverteilung, Schnittkonstruktion" Band 156, Forschungsgemeinschaft Bekleidungsindustrie, Hohenstein Institute, Köln, Germany, 2003.

[17] ISO - International Organization for Standardization, "ISO 7250-1: Basic human body measurements for technological design-part 1: Body measurements definitions and landmarks", Genf, Swiss, 2008.

[18] J. Beringer, S. Morlock, "Using 3D Scanning for Improved Helmet Design", Hohenstein Webinar, 2015 